\title{
Rules of the Road: Connecting Cities to Underutilized Freeway Infrastructure Zones through Parametric Urbanism
}

KARL DAUBMANN,

University of Michigan

QETUWRAH REED

University of Michigan
Transportation infrastructure such as waterways, roads, railroads or the federal highways have always informed the design of cities. The National Interstate and Defense Highways Act of 1956 forever changed transportation, economic flows, connectivity and the landscape of the US. The mechanical efficiency required for the success of the freeway is created through separation from everything that might slow it down but benefits of speed created by separation are constantly at odds with slower, finer-grained, human concerns of dense urban cores. Rather than negate the rich existing conditions of rustbelt city infrastructure, Rules of the Road engages the parametric, Fordist logic of the freeway with the requirements a modern city and proposes parametric urban design strategies that mitigate environmental, social, and formal concerns with an architecture that engages large swaths of under-utilized freeway infrastructure zones.

\section{INTRODUCTION}

The problem of designing transportation systems related to urbanism and architecture has existed since humans began migrating long distances. Roman roads allowed for movement across great distances for traders, pilgrims, and soldiers. These movements often created conflicts between those traveling and local villagers. ${ }^{1}$ As transportation speeds increase and urban areas have become denser, the problems have become even more complicated. Where the transportation routes once defined and connected keys points of urbanism, today the speed and mobility of the automobile is viewed as a threat to good urbanism. As a design problem, the concern for transportation in close proximity to urbanism presents multiple dualities that are worth considering. From a visual and scenography perspective there is both the view of the infrastructure from the city and the ability to get elevated views of the city from this same infrastructure, both inside and outside of the infrastructure. Large scale regional transportation routes highlights the differences between being from a place and one who is passing through, local versus tourist, belonging and being an outsider. As we rely on faster machines for transportation, the speed differentiates the pedestrian 
from the passenger. Where so many dualities exist, simple binary solutions appear that either choose only one or provide solutions that are unable to address both halves of the duality.

The complications created by the proximity of transportation systems to other elements, urban or otherwise, have often seemed too complicated to address. As a result, a reductive mode of separation has been the prevailing design solution. During the Middle Ages the problem of clear sightlines was taken up by Edward I as a means to deter theft and murder of those engaged in regional transport. The Statute of Winchester in 1285 highlighted the expectation of clear and safe passage by creating a 200 foot right of way on each side of a regional road for clear sightlines. The statute stated that by decree 'there be neither dyke nor bush whereby a man may lurk to do harm'. It went onto to state that if a landowner did not clear the right of way and theft or murder occurred, then the landowner was responsible. There is already the biasing of the unobstructed movement in service of commerce and military needs over that of the adjacent local property. Additionally clear logistical and dimensional requirements are created and embedded in our understanding for the design of transportation systems.

The invention of the automobile and subsequent manufacture in the US had a profound impact on transportation, infrastructure, and urban settlement patterns. Prior to World War I there were 5 million cars and trucks registered in the US and in ten years following the quantity increased to five times that number. ${ }^{2}$ The origins of the US interstate highway system begins with the Federal-Aid Highway Act of 1938 that chose a toll-free interregional network approach over a network of three north-south and three east-west toll superhighways to connect the whole United States. Building on this work, congress passed the Federal-Aid Highway Act of 1944. The act funded $50 \%$ of the construction costs and began 40,000 miles of roadway construction to connect cities, industrial centers, and key border crossings to support commerce and national defense. Because the initiative was a cost-share with state level funding, there was no comprehensive plan created. By the mid 1950's only 6,500 of the 40,000 miles of interstate highway had been completed. For national interest the National Interstate and Defense Highways Act of 1956 raised the federal cost share to $90 \%$ in order to complete the interstate highway system and became the largest public works program undertaken to that point in history. ${ }^{3}$

Because the highway was a latecomer to urban settlement, the planning for such projects adopted an approach of avoidance related to highway placement. The avoidance at a large scale was seen through the proposals like that of the townless highway by Mackaye and Mumford in "Townless Highways for the Motorist". ${ }^{4}$ MacKaye the designer of the Appalachian Trail worked with Lawrence Halprin to reconcile the growing needs of technology while preserving the social, urban, and natural landscape conditions. Guidelines published by the American Association of State Highway Officials in 1957 in A Policy on Arterial Highways in Urban Areas offered suggestions of placement of urban freeways in order to minimize cost and disruption to the city. The suggestions included wedges of unused land, between ribbons of development, blighted areas slated for development, adjacent to rail lines or shores, or along the edge of already publicly owned parks or tracts of land. ${ }^{5}$ What originates as avoidance tactics leaves us with a legacy of major infrastructure acting as urban walls or separation resulting from these decisions in Chicago along the lake and Boston along the river.

Throughout the development of the highway system there have been heated debates about where and how best to plan and locate the necessary infrastructure. Many disciplines fought for a stake from engineering to planning, landscape, and architecture. The politics surrounding these planning projects was intense. With the exception of a few early examples of multidisciplinary teams in the late 60's like that of the Baltimore's Inner 
Harbor lead by SOM, ${ }^{6}$ the "design' of highways has resided mainly in the domain of traffic engineers. What might the discipline of architecture be able to offer to the discussion now? Can architecture be redeployed to mediate the scale difference between infrastructure and city? Are there architectural maneuvers or methodologies that can be deployed to rethink aging infrastructure?

\section{DESIGN THINKING}

In The Design of Business, Roger Martin uses the metaphor of a "knowledge funnel" to describe the development of an idea from mystery to heuristic to algorithm. As ideas move down the funnel they become easier to manage, execute and exploit. The ease of executing the algorithm is made possible because additional (and not always extraneous) information is shaved away. He proposes that businesses need to both exploit algorithms while simultaneously exploring new mysteries as part of a research and development campaign to develop new ideas, products and identify new markets as a means of staying competitive. Through a number of case studies Martin demonstrates the downfall of companies that focus solely on executing the algorithm because the market is constantly evolving. Mysteries might be difficult to develop but the potential for large benefits exists. As a cautionary tale, of the first Fortune 100 companies identified in 1955 only 11 still exist today, demonstrating the need for constant innovation in order to stay relevant and current. ${ }^{8}$ Compare this low success rate over a long term to the lack of new knowledge being deployed related to the design of highways. It is easy to then apply this same metaphor toward the highway building program of the 1950's. It becomes clear that the development of an algorithm was deployed as a means to deliver the requested mileage in a short period of time, and much of the developmental practices ceased after this point. Using Martin's prompt to reinvest in the mystery, it is important to understand how much has changed and what potential might exist for new and innovative approaches and algorithms.

What Martin calls a mysterious problem, others might characterize as a wicked problem. ${ }^{9}$ Given the nature of wicked problems in that they have no stopping rule, lack true or false solutions, and are unique, the ability for a design practice to take on such problems is incredibly limited given the financial burden of a service based industry. In contrast, the academic setting and academic practices are well-suited to take on these problems as a means of introducing students to the difficulties and realities of high-value design problems. ${ }^{10}$ Ideally a collaboration could exist between professional practices with on the ground expertise and real commissions with an academic think-tank to provide a broader research and application perspective.

The urban highway was taken up as a design research topic and high-value problem because of its impact on large populations of people, its impact on multiple American cities, its rule based logic of geometric form, the need to address an increasingly aging infrastructure, and new technologies that threaten to undermine the prevailing rules for the highway system. As early as 1953, a period where Detroit was producing some of its largest cars, Lewis Mumford yearned for smaller electric cars with urban virtues of maneuverability and small parking footprints. ${ }^{11}$ Electric and hybrid technologies are reducing or eliminating sound and pollution from cars. Autonomous technologies are addressing safety and traffic. Carpooling and ride sharing are taking on the financial burden of ownership and traffic. Projects like MIT Media Lab's "Reinventing the Automobile" addresses the design of the car and highlights the subsequent potential impact on the city from a broad stroke policy perspective. ${ }^{12}$ Emissions, sound and safety were all very good reasons to provide greater distances from highways and buildings but as each of those topics are taken up by recent advances in automotive design it becomes an increasingly relevant exercise to rethink the long held beliefs about urbanism and transportation infrastructure from an architectural perspective. 
Because it was the traffic engineer that became responsible for the design of transportation, many of the guidelines biased the quantitative, logistical, and algorithmic. Since the 1960's the early computer was used to make calculations and validate design strategies. In a 1973 report prepared by the OECD Research Group computational and optimization approaches highlighted potential benefits for design related issues of alignment in plan, alignment in section, and road link design. The design optimization impacted cost control and showed savings of $15 \%$ on related earthwork. The specific applications demonstrated in the report were all for rural road design because of "complication of the costs of land and structures in urban areas". To put this work in technological context, at the time results were transferred from one program to another through the use of cards, paper tape, and magnetic tape. ${ }^{13}$ It is important to note that much of the future development work identified by the report addressed access to high quality data. The need for high quality data is becoming more available and recently more accessible through crowdsourcing, GIS applications and growing capabilities of recent big data initiatives.

Parametric modeling has advanced the ability to manage complex geometry and develop rule based models. Given obvious advances in computation, the logistics and algorithms native to the highway system were reconceptualized as a series of rules and parameters. Parametric modeling offers a means to manage the complexity of mass-customization while coordinating logistical constraints. Given the nature of rule-based designs that they do not necessarily lead to singular solutions, parametric modeling was chosen for its ability to simulate and represent multiple possible scenarios. Where non-parametric approaches must freeze design at one stage to progress to the next stage, the use of CATIA meant that early design decisions and parameters of rules could be tweaked even late in the design process. The intention is to develop this mode of working as a means of supporting a community planning process where the need to visualize possibilities exceeds the need for one final design proposal.

\section{PRECEDENTS}

There are a few early examples of architects using architecture to engage transportation and infrastructure. The car and movement were considered hallmarks of modernism and the language and form become inspiration for the precedents. Additionally architects understand urban context and it's value to see the way that various sites and urban conditions might inform both the architecture and the infrastructure.

As a traffic study project in Philadelphia in 1952, Louis Kahn devised a series of diagrams based on a governing principle that traffic should move based on hierarchical function. That is to say this new method of organization and movement throughout the city would be based on the functionality of different programmatic elements. What results is a condition in which the city dissolves away and only the conditions of movement begin to describe the functions of the city as a means to guard oneself from the ever present movement of the automobile.

In 1939 Norman Bel Geddes designed Futurama which proposed an infrastructural layout for the projected future of 1960's America. As Geddes was convinced of the notion that America would be fully integrated with automobiles by this point, Futurama becomes a means to advocate for a future living condition that embraces the density of the highway infrastructure. It also stands as a utopic vision that if actually realized would be a dystopic reality.

In 1910, Edgar Chambliss proposed a linear structure which integrates the extremities of residential and transportation conditions. Through a systematic layering of infrastructure, the residential corridor is placed up and away from the noises and barrages of traffic and roadways which cover a train station at the lower levels. While Roadtown stands as 
seemingly extreme example, these conditions fully advocate for the integration of the automobile into society, which speaks to a forward way of the thinking for the first half of the 20th century. Much like Roadtown, Sir Geoffrey Jellicoe's Motopia maps this style of layered infrastructure to the entirety of the city rather than separating the urbanism and infrastructure of 1959. In this instance, all automotive activity is raised to the roof whereas all pedestrian activity takes place at the ground. What results is an undisturbed landscape condition blanketed with architecture, holding automotive infrastructure above and out of view. While not directly dealing with the evolution of freeway infrastructure these design projects propose alternate views to infrastructure occupation and begin to help fuel the question of possibilities within architecture and highway infrastructural integration.

\section{DESIGN RESEARCH-RULES OF THE ROAD}

The highway is an important design element and construct of the 20th century. This element determines major urban distributions, migrations, and impacts. The urban highway is a major contributor to the design of cities. In most instances the transportation infrastructure is viewed negatively as a visual liability and is nearing the end of its lifetime. This presents a high value problem with impact in population and urban form. The problem is further complicated by difficulties in jurisdiction, land use, and emerging new technologies.

This research began with Chicago given its dependency on connectivity as a nexus of the United States. Rail lines and highways were a huge part of the mail order industry that began in Chicago. When the Dan Ryan Expressway was constructed in 1961 it was the busiest and widest highway in the world. The Research on the City Grant provided by Taubman College of Architecture and Urban Planning supported all research and design proposed for Chicago.

Detroit is the second city being studied as a rust belt urban center with a surplus of transportation infrastructure. Detroit offers an intriguing case study because of its strong automotive history. In comparison to Chicago where the urban transportation network is tightly constrained, Detroit has much more open space and more diversity of transportation morphology. The University of Michigan Office of Research Grant was awarded to extend research and design proposals for Detroit as a means of being able to compare and contrast as series of Rust Belt cities.

After acquainting ourselves with a comprehensive spectrum of historical precedent dealing in infrastructure, it became pertinent to choose sites within Chicago that exuded complexity in their pre-existing condition. Four complex interchanges were chosen for study: the northern exchange at I-94, the interchange at the South Loop at I-290 and I-94, the South Side interchange I-55 and 1-94, and the strip of infrastructure situated on I-94/I-90 between I-290 and I-55. Of the highway infrastructure situated across the city, these proved to be moments of potential for mediating infrastructure with architecture as defined by preexisting spatial and traffic conditions. The northern exchange was unique in that it was a three way interchange which essentially fed and diverted traffic into and away from the freeway. The South Loop is hybridized roundabout condition that incorporates a tangled series of curves which became aptly known as the Spaghetti Bowl. The strip of freeway between I-290 and I-55 provides an interesting condition in that the series of continuous on and off ramps begin to create a new system of infrastructure with consistent moments of the structure visibly peeling away from itself. The South Side connection is a double interchange condition connected at a single point through a mutual southern highway at I-55 and adjacent to the river.

While performing preliminary analysis, it quickly became clear that gaining more knowledge about pre-existing freeway conditions would be beneficial before creating any new designs. This line of thinking led to the creation of an extensive taxonomy of pre-existing interchange 
condition diagrams, which simply demarcate the common formal trends of the system which will later influence the consciousness of design possibility.

What followed was a series of site analysis drawings and three dimensional models which give a much more precise visual of all formal site conditions. From here, the spatial qualities of the models were studied and manipulated in CATIA, the main modeling/design platform used in this project to quickly move the designs through a series of parameters which alter the form, occupation, and efficiency of all included spaces. Formal parameters were added to the preexisting spatial conditions and methodically transformed along a range of possibilities. Mapped out on a much larger scale, this practice occurred repetitively with varied formal constraints until resulting designs addressed multiple synthetic concerns as a means of overcoming reductivist and binary solutions. At this point in the study, the outputs were then assessed architecturally for their feasibility in construction as well as their possibility for increased and mixed programmatic activities. The designs that qualify for this portion of design development are then narrowed down, which subsequently receive a comprehensive design solution. This includes program, materials, systems, as well as further analysis of the effects that this new design will have on the pre-existing highway condition, which in some cases had been shifted out of its original position. The final product of this result is a sensitive architecture that fully accommodates all parametric constraints set and ultimately challenges the notion of usable space within the city condition.

\section{O'HARE AIRPORT}

A zone exists between the city of Chicago and the area defined by O'Hare International Airport. In this space it is a mix of city, state, and federal jurisdictions. Much like the highway that requires buffer zones as a means to mitigate speed differences between local and regional transportation, the airport also uses large setbacks to address the speed and sound of the runways. In this space multiple highways converge.

The Masters of Science Digital Technologies capstone studio explored the infrastructural zone adjacent to the airport. The approach was to investigate the highway space and explore possibilities for large scale planning related to deploying the highway as a means of defining space and urban patterns. By looking at flows and points of connection, horizontal geometry and patterns were explored. Rather than attempting to minimize the highway, an impossible task, we used the highway to create resulting urban structure. The broader pedagogical goal was to identify a topic, learn about its limits and rules, develop an understand that allows the material to become malleable, and then deploy that knowledge

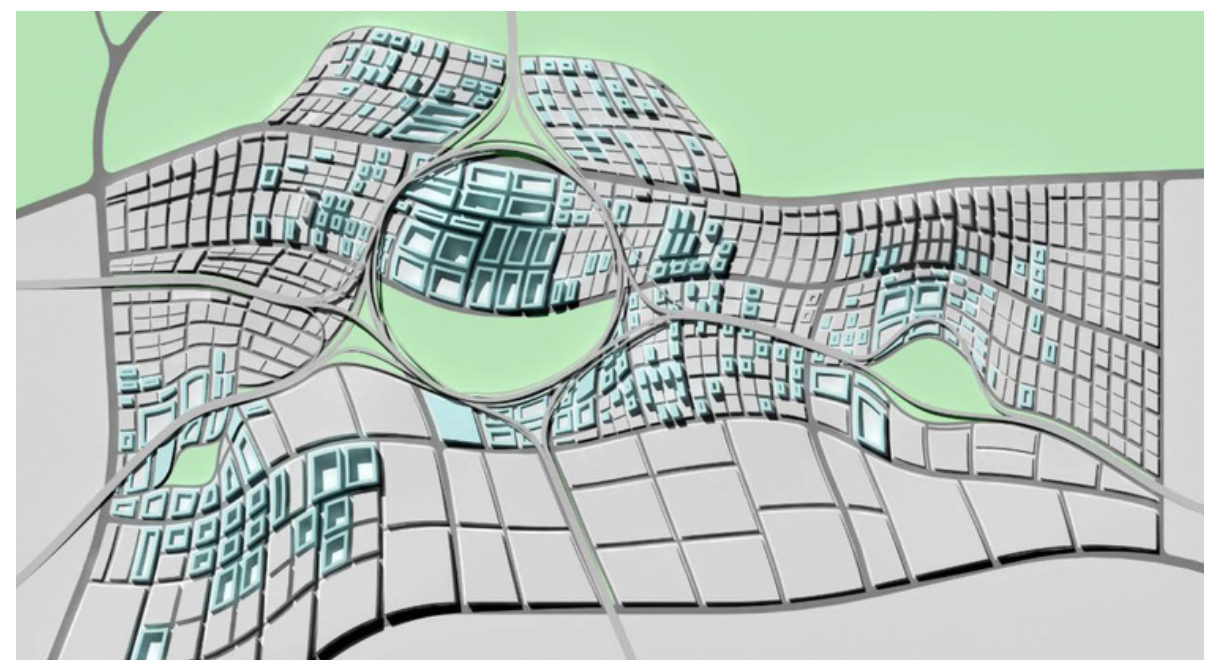

Healthy Resilient Communities
Figure 1: Plan developed by MSDT capstone using super scaled roundabout. (See credits.) 

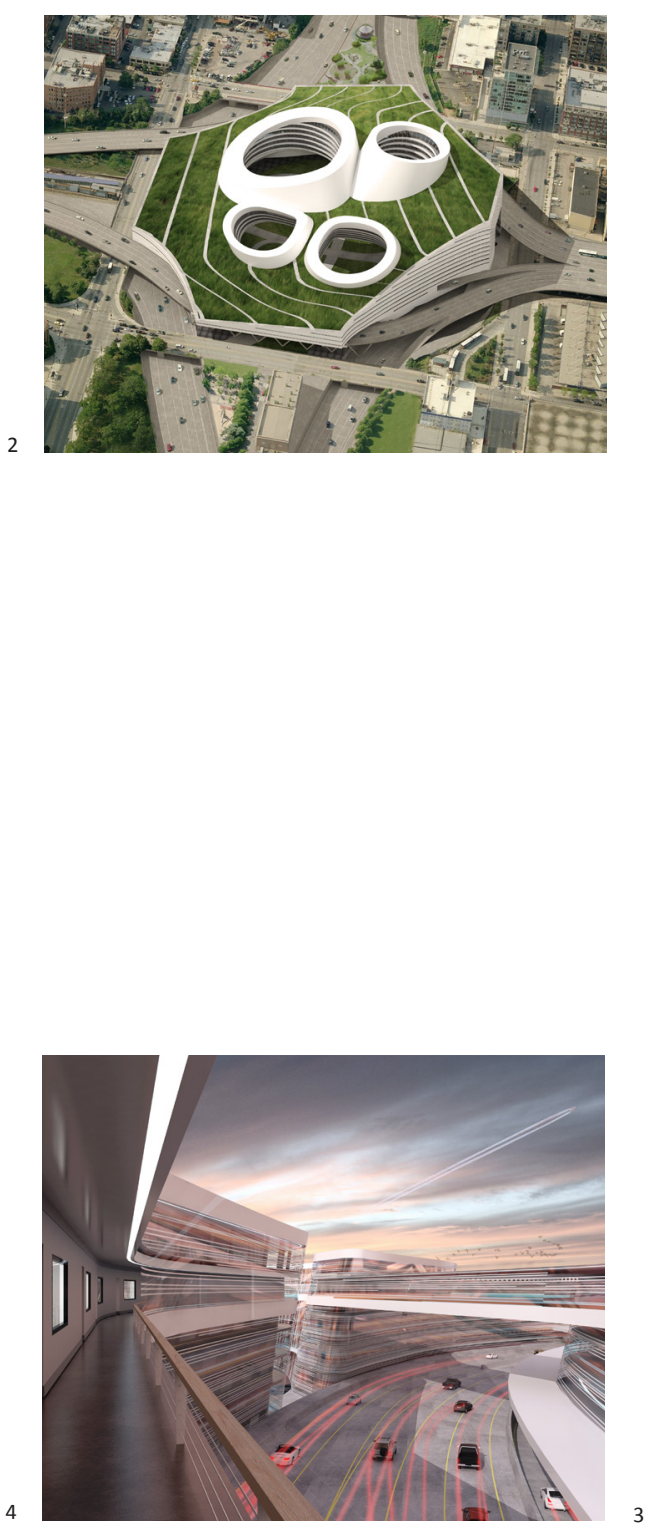

Figure 2: Aerial view of South Loop site.

Figure 3: Section perspective of South Loop site.

Figure 4: Aerial view of South Side site. Figure 5: Section perspective of South Side site. (See credits.) in a synthetic design application. While this work supported the Rules of the Road, the approach is imagined to be a transferable design/research approach.

\section{CHICAGO LOOP}

The Loop or Spaghetti Bowl in Chicago represents a massive urban block devoid of activity due to the highway. As a mode of avoidance, the highway was dropped into the void created by the Burnham Plan of 1909. What was originally reserved as a public civic plaza became a space for the automobile. As a means of testing the proximity of a human to a car, the proposals seeks to re-occupy the space in a large scale public manner without displacing the infrastructure. A large office building is proposed with an exterior public parking space which occupies a cloverleaf landscape proposal. Rather than hide the automobile from the pedestrian, the car is viewed as a sculptural trajectory that carves into the mass of the block.

\section{SOUTHSIDE CHICAGO}

In contrast to the Loop, the South side site was used as a means to engage a neighborhood residential fabric. Where the Loop represented a depressed condition the Southside site included an elevated freeway. This site focused on the continuity of the freeway and
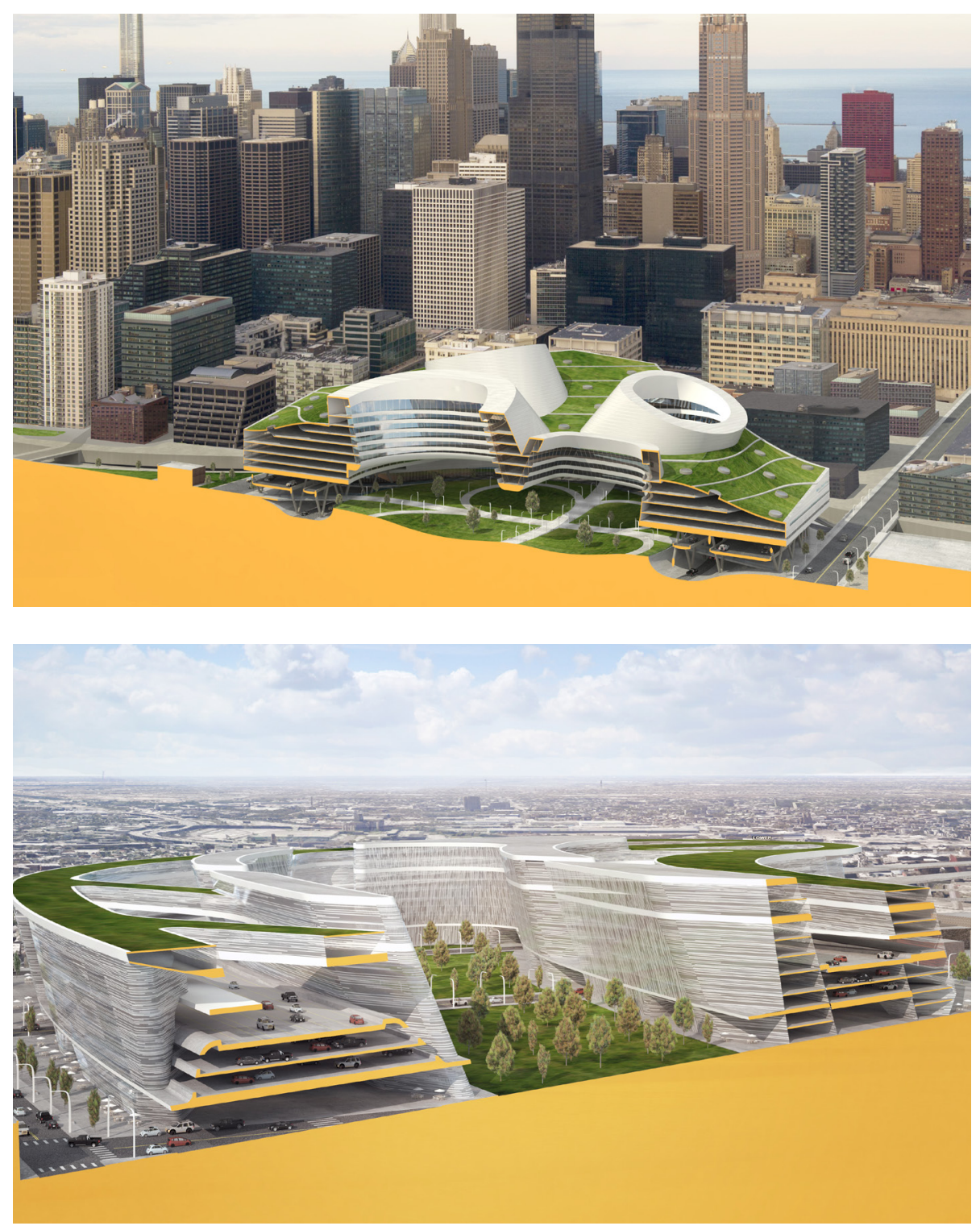

Intersections Between the Academy and Practice 
examined the potential for cross-cut penetrations at the street level and visually for the passengers on the freeway. The cross cuts allow for local movement across the site making connections to and through an urban landscape. The cross-cuts break down the large form and provide driver and passenger glimpses of the local urban fabric below.

\section{FUTURE DIRECTIONS}

The work carried out as Rules of the Road is viewed as a series of phases. The O'Hare work was done as a design studio so that it would uncover issues, predilections, and preconceptions of highway infrastructure. The two case studies of Chicago were then carried out as a design research project as a large-scale architectural proposal. This work was carried out with a limited scope as a means to encourage the process of making and have a proposal to generate discussion and possibilities. The final work for the Chicago phase was presented as part of an exhibition. With this work as a starting point, the next stage includes an urban planner on the team for the work in Detroit. In the Detroit work, policy and market concerns such as privatization of infrastructure and the potential impact of those decisions will be a significant area of focus. There are discussions currently happening in Detroit about removing parts of the urban highways and the intention of this project is to get involved in some of those ongoing discussions.

\section{PROJECT CREDITS}

Masters of Science Digital Technologies Capstone Studio: Prof Karl Daubmann with Emad Khaled, Chris Byerly, Ana Faria Delfino, Punam Jensen, Han-Yuan Tsao, David Zhu.

Rules of the Road - Chicago Design Team: Cezanne Charles, Karl Daubmann, John Marshall with Patrick Ethen, Ryan Goold, Mary Matucheski, Qetuwrah Reed.

Rules of the Road - Detroit Design Team: Karl Daubmann with Brock Hinze, Mark Keller, Susan Landfried, Qetuwrah Reed, Stella Zhang.

\section{ENDNOTES}

1. Crowe, Silvia, P.P.I.L.A. “One: History of Roads" The Landscape of Roads. London: The Architectural Press, 1960. 15.

2. Bugge, W. A, and W. Brewster Snow. "The Complete Highway." The Highway and the Landscape. New York: Rutgers, The State University, 1959. 9.

3. DiMento, Joseph F. C., and Cliff Ellis. "Chapter 5" Changing Lanes: Visions and Histories of Urban Freeways. Massachusetts: MIT Press, 2013. 116.

4. Halprin, Lawrence. Freeways. New York: Reinhold Publishing Corporation, 1966.

5. Bugge, W. A. A Policy on Arterial Highways in Urban Areas. Washington, D.C.: The American Association of State Highway Officials, 1957. 89.

6. DiMento, Joseph F. C., and Cliff Ellis. "Chapter 5" Changing Lanes: Visions and Histories of Urban Freeways. Massachusetts: MIT Press, 2013. 105.

7. Martin, Roger. "The Knowledge Funnel." The Design of Business: Why Design Thinking is the Next Competitive Advantage. Massachusetts: Harvard Business Press, 2009. 21

8. Martin, Roger. "The Balancing Act." The Design of Business: Why Design Thinking is the Next Competitive Advantage. Massachusetts: Harvard Business Press, 2009. 116.

9. Ritter, Paul. Planning for Man and Motor. New York: Pergamon Press Limited, 1964.

10. Kolko, Jon. "Wicked Problems" Wicked Problems: Problems Worth Solving: A Handbook and A Call to Action. Texas: Austin Center for Design. 2012. 10)Rittel, Horst W. J, and Melvin M Webber. "Dilemmas in a General Theory of Planning" Scotland: Elsevier Scientific Publishing Company, 1973. 155-169.

11. Mumford, Lewis. Highway and the City. New York: Harcourt, Brace, and World, Inc. 1953. 243.

12. Borroni-Bird, Christopher E, Lawrence D. Burns, and William J. Mitchell. "The New DNa of the Automobile." Reinventing the Automobile: Personal Urban Mobility for the 21st Century. Massachusetts: The MIT Press, 2010. 9-18.

13. Antoniotti, Monsieur P, P. Becco, Dipl. Ing. Peter P. Canisius, Mr. D. W. Farrend, Monsieur M. Peeters, Civil Engineer Ivar Schacke, Dr. Ing. Emanuele Scotto, and Dr. Ing. Matti U. Vuorio. Road Research: Optimisation of road alignment by the use of computers. France: Organization for Economic Co-operation and Development. 11

\section{REFERENCES}

Solomon, Jonathan D. 13 Projects for the Sheridan Expressway. New York: Princeton Architectural Press, 2004.

Verebes, Tom. "The City as Expression" Masterplanning the Adaptive City: Computational Urbanism in the Twenty First Century. New York: Routledge, 2014. 13-17. 